P176 (continued)

Results: Seven themes regarding misconception about child feeding practices emerged from the data. These included: a fat baby is a healthy baby; the baby is big because of genetics; cereal in the bottle helps the child sleep; a crying baby is a hungry baby; breast milk is not enough; juice is good for babies and children; and children need to drink a lot of milk.

Conclusions and Implications: Future nutrition education delivered to NJ WIC participants should offer content that considers invalid beliefs. Also, these findings should be replicated and explored in other locations.

Funding: Supplemental Nutrition Assistance Program Education

\section{P177 Online Nutrition Education for Child Care Providers: Technology Access, Interest and Experiences}

Katherine Speirs,PhD, kspeirs@email.arizona.edu, University of Arizona, 650 North Park Avenue, Tucson, AZ 85719

Objective: Early care and education is an important setting for promoting healthy eating. Child care providers need effective training and online education may be one way to provide it. This study explores child care providers' access to technology, interest in and experiences with online nutrition education.

Study Design, Setting, Participants: Three hundred and fourty-three Head Start teachers, center-based and home-based providers were surveyed.

Outcome Measures and Analysis: Self-report measures assessed providers' access to technology, interest in and experience with online training. Frequencies were used to describe the sample and Fisher's exact tests to explore associations.

Results: Ninety-nine perecent of participants used the internet: Ninety-four percent accessed the internet using a desktop computer, $57 \%$ a cell phone and $40 \%$ a tablet, no differences were found by age. Ninety-one percent of participants reported an interest in online training generally and $88 \%$ in online training about mealtimes. Three quarters found online training to be convenient. Thirteen percent reported learning better online, mostly because they were able to work at their own pace. Twenty-eight providers were not interested in online training. Thirtysix percent felt they learned better in-person, mostly because they were able to ask questions. Eighty-six percent of the sample had participated in online training. Centerbased and Head Start teachers were more likely to have participated in online training than home-based providers $(\mathrm{p}<.0001)$. Age was not associated with having participated in an online training.

Conclusions and Implications: Online training may be an effective mode for delivering nutrition education to child care providers. Online training should be compatible with desktop computers, cell phones and tablets; asynchronous; and allow participants to submit questions.

Funding: NIFA

\section{P178 The Use of Entertainment Education to Teach Nutrition Messages to Preschool Children: A Feasibility Study}

Caree Cotwright, PhD, LDN, RD, cjcot@uga.edu, University of Georgia, 280 Dawson Hall, Athens, GA 30602; Nathalie Celestin, MPH, University of Georgia; Jennine Delane, BS; Donna Holcomb, BA;

Nicole Motoyasu, BS; Dorothy Dupree, BS

Objective: The purpose of this study was to examine the feasibility of using an entertainment education to improve knowledge of and willingness to try fruits and vegetables (FV) among preschool children.

Study Design, Setting, Participants, Intervention: Researchers conducted a feasibility study in two phases. Phase One was implemented at a childcare center in Athens, Georgia for children ages 3 to 5 (Teachers $n=8$ and Children $\mathrm{n}=37$ ) with a pretest-posttest design. Phase Two was conducted in two Head Start Centers in NE Georgia (Teachers $\mathrm{n}=20$ and Children $\mathrm{n}=59$ ) with an intervention-control design. The six-week Freggie's Green Machine intervention included theater-based nutrition lessons and tastings for three fruits and three vegetables.

Outcome Measures and Analysis: Changes in preschool children's knowledge of and willingness to try FV were measured using McNemar's analyses. Generalized linear mixed models were performed to compare differences between the intervention and control group from pre to post-intervention.

Results: During Phase 1 teachers and parents reported high program satisfaction and children related to the Freggie characters. In Phase 2, participants improved knowledge of and willingness to try FV. For example, no children in the intervention group were able to identify kiwi at pretest, however, at post-intervention 35\% identified kiwi $(\mathrm{p}<0.001)$. There was a significant increase in proportion of children in the intervention group that could identify kiwi as compared to control group $(\mathrm{p}=0.0003)$. While there were no significant differences in willingness to try $\mathrm{FV}$, there were notable increases in trying kiwi and sweet potatoes.

Conclusions and Implications: Findings indicate that entertainment education is a feasible and promising way to teach nutrition messages to preschool children.

Funding: University of Georgia

\section{P179 Vegetable or Fruit? An Examination of Commercially Available Vegetable Products for Infants and Toddlers}

Kameron J. Moding,PhD, kameron.moding@ucdenver.edu, University of Colorado Anschutz Medical Campus, 12631 East 17th Avenue, Mail Stop F561, Aurora, CO 80045; Mackenzie J. Ferrante, MS, RDN, Colorado State University; Laura L. Bellows, PhD, MPH, RDN; Alyssa J. Bakke, PhD, Pennsylvania State University; John E. Hayes, PhD; Susan L. Johnson, PhD, University of Colorado Anschutz Medical Campus 
Objective: To analyze the macronutrient content of infant and toddler foods (ITF) containing vegetables in the United States.

Study Design: Company websites $(n=19)$ were used to create a database of commercial ITF's containing vegetables $(n=517)$. The following information was recorded for each product: name, ingredients, serving size (g), total calories, carbohydrates (g), and sugars (g) per serving. Ingredient lists were used to categorize products into the following groups: single vegetable $(n=48)$, multiple vegetable $(n=40)$, and vegetable/fruit $(n=150)$. Remaining products containing proteins or grains were excluded from this analysis.

Outcome Measures and Analysis: Analyses of Variance (ANOVAs) were used to compare the macronutrient content per serving across vegetable product categories.

Results: ANOVAs showed significant differences among the vegetable products for total calories, $\mathrm{F}(2,235)=$ $13.74, \mathrm{p}<.001)$, carbohydrates, $\mathrm{F}(2,235)=29.46, \mathrm{p}<$ $.001)$, and sugars per serving, $\mathrm{F}(2,235)=94.05, \mathrm{p}<$ $.001)$. Post-hoc tests revealed significant differences between the single and multiple vegetable products separately and the vegetable/fruit products for total carbohydrates and sugars (Ps $<.001)$. However, the single and multiple vegetable products did not differ significantly from one another on any macronutrient (Ps $>.05$ ).

Conclusions and Implications: Exposure to vegetable flavors during infancy increases the likelihood that these flavors will be accepted during later childhood. However, our data reveal that a substantial majority of commercial infant and toddler vegetable products contain fruits. The addition of fruits to vegetable products affects the flavors infants and toddlers are exposed to, and significantly increases the carbohydrates and simple sugars per serving.

Funding: None

\section{P180 WITHDRAWN}

\section{P181 Online ASA24 Training Manual Pilot- Tested with Expanded Food and Nutrition Education Program (EFNEP) Educators}

Lori Anderson Spruance, PhD, CHES, Brigham Young University; Deirdre Douglass, $M S, R D$, Westat;

Thea Palmer Zimmerman, MS, RD;

Patricia M. Guenther, PhD, RD, University of Utah; Karen Franck, PhD, University of Tennessee; Debie Head, EdD, RD, LD, CDE, University of Arkansas Division of Agriculture Cooperative Extension Service; Teresa Henson, BS; Nathan Millerberg, BS, Utah State University; Carla J. Moore, PhD, RD, University of Georgia; Kimberly Wilson-Sweebe, MS, South Dakota State University; Gina Wood, MPH, RD, LD, West Virginia University; Carrie M. Durward,PhD, RD, carrie.durward@ usu.edu, Utah State University, 8700 Old Main Hill, Logan, UT 84321

Objective: The purpose of this study was to evaluate an online training manual designed to teach paraprofessionals how to use the mobile version of the Automated Self-Administered 24-hour recall (ASA24-2016) to collect 24-hour dietary intake data.

Study Design, Setting, Participants: Nutrition educators from EFNEP programs in 17 states were recruited to complete an online training consisting of readings, videos, online activities, quizzes, and assisting two individuals in completing a dietary recall using ASA24. After completing the training, the educators were invited to complete a onetime online survey.

Outcome Measures and Analysis: The questionnaire assessed the training content, reading and comprehension level, and appearance and design of the manual. Descriptive results were summarized for each domain.

Results: Twenty-five educators completed the online training and 14 (56\%) completed the online questionnaire. Most of the survey respondents took 4-7 hours to complete the training $(9 ; 64 \%)$. The majority identified as White $(11 ; 79 \%)$ and female $(13 ; 93 \%)$. The majority of respondents $(8 ; 57 \%)$ utilized both the 